\title{
A IMPORTÂNCIA DA SAÚDE BUCAL PARA ADOLESCENTES DE DIFERENTES ESTRATOS SOCIAIS DO MUNICÍPIO DE RIBEIRÃO PRETO*
}

\author{
Marina Sá Elias** \\ Maria Aparecida Tedeschi Cano*** \\ Wilson Mestriner Junior ${ }^{* * * *}$ \\ Maria das Graças Carvalho Ferriani*****
}

ELIAS, M.S.; CANO, M.A.T.; MESTRINER Jr. W.; FERRIANI, M.das G.C. A importância da saúde bucal para adolescentes de diferentes estratos sociais do município de Ribeirão Preto. Rev.latino-am.enfermagem, Ribeirão Preto, v. 9, n. 1, p. 88-95, janeiro 2001.

O objetivo do presente estudo é conhecer a importância da saúde bucal para adolescentes de diferentes estratos sociais, identificando a importância da estética dental, e o cuidado que estes dispensam em relação a sua saúde bucal. O processo metodológico adotado nesta investigação é de natureza qualitativa, utilizando como técnica de coleta de dados a entrevista semiestruturada. Conhecemos a importância da saúde bucal em vários contextos de suas vidas, como na aparência pessoal, na sexualidade, no emprego, e na saúde geral. Esta investigação permite-nos conhecer as motivações para os adolescentes preservarem sua saúde bucal, o que acreditamos ser muito válido no intuito de desenvolvermos a promoção de saúde através da educação em saúde.

UNITERMOS: adolescência, educação em saúde, estética dentária, saúde bucal

\section{INTRODUÇÃO}

$\boldsymbol{A}$ inda nos dias de hoje, apesar do grande avanço da odontologia em termos científicos e estruturais, a cárie é uma doença que atinge precocemente a população, fazendo com que as crianças percam seus dentes permanentes, chegando na adolescência desdentados, ou com dentes mal posicionados devido à falta de tratamento ortodôntico preventivo. Refletimos que isso deveria ser um problema para essas pessoas durante o seu convívio social, pois acreditamos que principalmente devido às particularidades da faixa etária estudada, a saúde e a estética bucal se tornam importantes para a auto-imagem, e um convívio social normal, pois, segundo CHAVES (1986, p.429) a saúde bucal é um componente da saúde e esta um componente do bem-estar ou felicidade individual. O conceito humanista de felicidade individual é associado ao de vida plena, fecunda, ativa; pressupõe convívio, participação, vida familiar e social.

\subsection{Raízes históricas}

A odontologia, como as demais ciências da área da saúde, passou por várias etapas na sua trajetória, iniciando com o empirismo, na idade antiga, passando pelo pré-cientificismo nos séculos XVI e XVII, até o surgimento de escolas especializadas na prática odontológica, iniciando assim a fase Científica. Na idade antiga, a odontologia era praticada em diversas civilizações, fato confirmado em achados arqueológicos.

Os primeiros terapeutas dentais eram médicos,

* Artigo elaborado com base na dissertação de mestrado de Marina Sá Elias, apresentada na Escola de Enfermagem de Ribeirão Preto da Universidade de São Paulo, sob a orientação da Professora Doutora Maria Aparecida Tedeschi Cano

** Cirurgiã-Dentista, Mestre em Enfermagem e Saúde Pública pela Escola de Enfermagem de Ribeirão Preto da Universidade de São Paulo, Professora de Introdução à Odontologia Preventiva e Sanitária e Estágio Supervisionado - UNIFRAN. Endereço: Rua: Wlamir de Lima Pupo, 374 - Lagoinha - 14095-300 - Ribeirão Preto - São Paulo - Brasil

*** Professor Associado do Departamento de Enfermagem Materno-Infantil e Saúde Pública da Escola de Enfermagem de Ribeirão Preto da Universidade de São Paulo. Endereço: Av. Bandeirantes, 3900 - Monte Alegre - 14040-902 - Ribeirão Preto - São Paulo - Brasil

**** Professor Doutor do Departamento de Clínica Infantil e Odontologia Preventiva e Social da Faculdade de Odontologia de Ribeirão Preto da Universidade de São Paulo e Professor Doutor da UNIFRAN

***** Professor Titular do Departamento de Enfermagem Materno-Infantil e Saúde Pública da Escola de Enfermagem de Ribeirão Preto da Universidade de São Paulo 
mas já na Idade Média os cirurgiões-barbeiros europeus se especializavam no tratamento de dentes. Estes profissionais trabalhavam à custa de tentativas e erros, e também por observação, e suas terapêuticas e diagnósticos eram baseados em rituais mágicos e religiosos.

O tratamento estético dentário, data de mais de um milênio antes de Cristo. Há na história, repetidas referências ao valor atribuído a substituição de um dente perdido. O senso de estética é muito influenciado pela cultura e auto-imagem. O que uma cultura admite como mutilado, desfigurado, pode ser belo para outra. Alguns povos limavam seus dentes incisivos em forma pontiaguda, para aumentar a ferocidade de sua aparência, já outros pintavam seus dentes.

BALDWIN (1980) nos lembra que as relações entre a estética e a saúde oral, particularmente, a saúde dental são complexas, e envolvem dimensões sociais, culturais e psicológicas. Mas é importante salientar, que a estética dentária se fundamenta em uma base mais sólida: a melhora geral da saúde dentária. É muito importante ver a odontologia em uma perspectiva de promoção de saúde, não apenas cuidando da saúde bucal, mas sim do indivíduo, com os seus medos, angústias e prazeres, ou seja, de uma forma integral.

Partindo da odontologia que era feita no passado, quase que exclusivamente mutiladora e reparadora, juntamente com os novos conhecimentos científicos adquiridos na década de 60 , em relação aos fatores causais da doença cárie, ficou claro que a forma como estava sendo concebida a odontologia, não se conseguiria atingir a saúde bucal, e a partir daí começou a surgir no Brasil uma nova forma de se ver a odontologia, que teve início em 1960. A odontologia preventiva seduziu inicialmente apenas alguns setores universitários. Mas passou por muitas críticas, a ponto de ser vista como "coisa de poetas" ou ainda "coisa de comunistas" até que nos anos 80, com o desenvolvimento de novos conhecimentos, e a absorção da experiência de outros países, foram quebradas as barreiras por aqui (NARVAI, 1994, p. 40).

Mas os conceitos da odontologia preventiva foram assimilados de forma incorreta, pois dos anos setenta aos oitenta tivemos a odontologia curativa, e o modelo vigente era o cirúrgico restaurador. $\mathrm{O}$ uso indiscriminado do selante é uma versão moderna do conceito da necessidade de obliterar sulcos e fissuras para impedir o desenvolvimento de lesão nesta superfície (MALTZ \& CARVALHO, 1997).

Já dos anos oitenta aos noventa tivemos métodos isolados de prevenção em nível individual. Como os dentistas estavam acostumados a passividade dos pacientes, passaram a dar prioridade às medidas preventivas voltadas para o atendimento individual, sendo privilegiadas ações como: aplicações tópicas de flúor, aplicação de selantes e profilaxias.
Podemos dizer que dos anos 90 até a presente data, o que se tem visto na odontologia, é um lento, mas constante caminhar, no sentido de incorporar o conceito de Promoção de Saúde em sua forma de lidar com a saúde bucal. Segundo CAPRA (1982) a nova concepção de saúde é holística e ecológica, enfatiza a inter-relação e interdependência essencial de todos os fenômenos.

Entendemos promoção de saúde como o processo de capacitação da comunidade para atuar na melhoria da sua qualidade de vida e saúde. Este novo modelo de prática, se tornou viável em grande parte pela ampliação do conceito de cárie e de doenças periodontais. A cárie, por exemplo, é atualmente considerada uma doença infecciosa e transmissível, e não apenas sinônimo de uma lesão. Desta forma, atualmente, tratar a cárie dentária não será apenas retirar a lesão, e a substituir por material restaurador, mas sim interferir no desequilíbrio que ocasiona a doença.

Os conhecimentos atuais disponíveis sobre a dinâmica do processo carioso, mostram que o desenvolvimento de uma lesão depende do nível de atividade metabólica das bactérias cariogênicas presentes, que por sua vez é influenciado por fatores variáveis que podem afetar o ecossistema saliva-placa-dente. Tudo isso, tendo como pano de fundo os condicionamentos sócioeconômicos-culturais a que as pessoas estão submetidas.

\subsection{Educação em saúde}

Com todos esses conhecimentos acumulados, o que se espera do cirurgião-dentista, é no mínimo a transmissão do conhecimento através da educação para a saúde. A odontologia tradicionalmente é uma profissão que vem colocando seus pacientes em uma condição passiva em relação ao seu problema, pois o que rotineiramente acontecia, era o surgimento de problemas bucais, e quando esses estavam estabelecidos, e em estágio avançado, o paciente buscava ajuda para "eliminar" o problema, ou seja, extrair os dentes.

Surgida do atendimento individual, a odontologia se restringia em limitar o dano, substituindo os dentes perdidos por elementos protéticos. Para tais procedimentos, o envolvimento do paciente se limitava em mostrar ao dentista a localização da dor, sua freqüência e intensidade. A odontologia vinha caminhando contra os conceitos de autocuidado, onde o paciente deve através de decisões pessoais, com a finalidade de prevenir, diagnosticar e tratar qualquer desvio de sua própria saúde, empreender esforços que levam a mudanças individuais de comportamento, com o objetivo de se tornar responsável por sua própria saúde. Para se chegar a isso o paciente precisaria ser educado, informado e motivado para cuidar de sua própria saúde.

MENDES (1996) cita que a carta de Ottawa elege 
a educação para a saúde e as políticas públicas, como pontos centrais para a consolidação prática voltada para a melhoria da saúde das populações. Devemos utilizar a educação como um instrumento de transformação social. Não só a educação formal, mas toda ação educativa que propicie a reformulação de hábitos, aceitação de novos valores e que estimule a criatividade. A educação deve ser pensada como um processo capaz de desenvolver nas pessoas a consciência crítica das causas reais de seus problemas.

Segundo DeBIASE (1991) os adolescentes apresentam um desafio para a comunicação, pois em seu esforço para ganhar independência, eles, freqüentemente, resistem a conselhos de uma figura de autoridade. A autora acredita que, determinar o que motiva o adolescente é o primeiro passo para o sucesso da educação em saúde dental. Também crê, que os adolescentes são mais facilmente motivados pelos esportes, aparência e popularidade.

Segundo GAGNÉ (1974) a importância da motivação no processo educativo é largamente reconhecida, e para isso não devemos nos esquecer de criar essas condições prévias e adicionais de aprendizagem, e também mantê-los interessados à medida que a aprendizagem vai ocorrendo, criando novas condições que os influenciem.

DeBIASE (1991) define motivação, como as forças internas e externas que dirigem e empurram a satisfação de uma necessidade. O processo de motivação envolve quatro fatores básicos que são: força motriz, ação individual, necessidade ou meta a ser alcançada, e algumas formas de satisfação de necessidades individuais. A autora ainda afirma que o educador em saúde bucal deve identificar as fontes da motivação.

\subsection{Adolescência e auto-imagem}

Segundo CAVALCANTI (1988) a adolescência é a fase de crescimento biopsicossocial que vai da infância à idade adulta, para que seja uma experiência equilibrada de vida, deve implicar num crescimento solidário biológico, sócio-cultural e psicológico. É um período caracterizado por várias mudanças corporais e adaptações a novas estruturas psicológicas e ambientais.

No que diz respeito ao desenvolvimento psicossocial do adolescente, INFANTE (1994, p.550) cita que uma das características presentes no adolescente é a busca de identidade, ou seja, o adolescente tenta determinar-se diante dos papéis sociais disponiveis, buscando modelos. O jovem volta-se para os aspectos estéticos de sua cultura como forma de comparar o seu corpo com um modelo. Na nossa sociedade, onde é consenso a importância de uma boa aparência física não causa espanto, dizer que, obviamente a perda de um ou mais dentes, implicaria em grandes alterações emocionais para estes. Tendo sua auto-imagem prejudicada o adolescente pode perder sua auto-estima fazendo com que isto interfira em seus relacionamentos pessoais, além de eventualmente produzir sentimentos de inferioridade.

CAVALCANTI (1988) afirma que, em parte, a imagem que o adolescente forma do próprio corpo é derivada dos estereótipos culturais, produto de suas vivências na interação social, e também, o resultado de suas próprias expectativas e fantasias.

O desejo de possuir uma boa aparência não é mais encarado como sinal de vaidade. Em um mundo tão competitivo, boa aparência é literalmente uma necessidade. JENNY \& PROSHEK (1986) mostram que as ocupações consideradas de prestígio, ou onde os funcionários são vistos pelo público, estes, devem possuir uma boa estética dental. Ocorre ainda a influência de uma boa aparência física em entrevistas de emprego.

No que diz respeito à sexualidade, não podemos deixar de citar o beijo, uma manifestação de carinho que pode ser prejudicada se a boca apresentar mau-hálito devido à falta de higiene bucal adequada, dentre outros motivos que também poderiam ocasionar o problema de halitose. No nivel psicossocial, uma boca sadia garante a manutenção da boa aparência, da expressão e da comunicação interpessoal, sendo assim, um fator da maior importância na preservação de auto-estima (WEYNE, 1997, p.23).

Os dentes muitas vezes se tornam, a característica mais decisiva na formulação de nossos julgamentos. Através da face, uma região sempre exposta do corpo humano, a estética bucal comprometida, pode se tornar um motivo de ansiedade. Como componente essencial da imagem corpórea os dentes podem originar sentimentos que variam desde constrangimentos até profunda ansiedade (GOLDSTEIN, 1980, p.7).

Desta forma, buscamos conhecer a importância da saúde bucal para adolescentes de diferentes estratos sociais do Município de Ribeirão Preto. E como objetivos específicos, selecionamos: identificar a importância da estética bucal para adolescentes de diferentes estratos sociais do Município de Ribeirão Preto, e conhecer o cuidado que os adolescentes de diferentes estratos sociais do Município de Ribeirão Preto, dispensam em relação à sua saúde bucal.

\section{METODOLOGIA}

Em nossa pesquisa, foi utilizada a metodologia qualitativa fundamentada em MINAYO (1996). Utilizamos o recurso da entrevista semi-estruturada e, para registrar as falas, utilizamos um gravador. A 
entrevista partiu de um roteiro que difere do sentido tradicional de formulário. O roteiro contém poucas questões, é um guia.

Utilizamos ainda, para a compreensão e análise dos objetivos propostos por este estudo referentes à estratificação social, STAVENHAGEN (1966) e SILVA (1981).

Na perspectiva que nos orienta e tendo em vista o desenvolvimento de nossa pesquisa, utilizamos como referência RIBEIRO (1999), que estabeleceu divisões econômicas entre as diversas áreas da cidade utilizando dados do IBGE (Instituto Brasileiro de Geografia e Estatística), referente à localização dos domicílios e a distribuição de renda por chefes de família residentes, e desta forma utilizaremos os critérios formulados pela autora, que são: a) Bairros de estrato sócio-econômico baixo foram aqueles que continham $70 \%$ ou mais da população de chefes de família com rendimento inferior a 5 salários mínimos; b) Bairros de estrato sócioeconômico médio-baixo continham entre $45 \%$ e $70 \%$ dos chefes de família com salários inferiores a 5 salários mínimos; c) Bairros de estrato sócio-econômico médioalto são aqueles que continham 20 a $45 \%$ dos chefes de família com menos de 5 salários mínimos; d) Bairros de estrato sócio-econômico alto - quando a porcentagem de chefes de família com rendimento inferior a 5 salários mínimos foi menor que $20 \%$.

Devido a impossibilidade de trabalhar com todas as escolas, optamos pelo sorteio, conscientes de que a escola sorteada representaria o estrato social a qual estava classificada, devido à relativa homogeneidade de cada uma delas. Com relação ao sorteio das escolas particulares, decidimos trabalhar somente com as que apresentassem mensalidades de 2 salários mínimos ou mais, onde supúnhamos encontrar uma clientela mais diferenciada economicamente.

Após serem identificadas e classificadas de acordo com o critério de estratificação social usado como referencial nesta pesquisa, sorteamos 1 (uma) escola representante de cada estrato social. As escolas sorteadas foram: Baixo - Escola Municipal de Ensino FundamentalEMEF. Profa. Neuza Michelutti Marzola, Médio baixo Escola Estadual-EE. Alberto Santos Dumont, Médio alto - Escola Municipal de Ensino Fundamental-EMEF. Prof. Anísio Teixeira, Alto - Particular. Vita et Pax. A opção por fazermos a pesquisa em diferentes estratos sociais, se torna relevante porque acreditamos que existam diferenças na valorização e na importância dada à estética bucal pelos atores sociais dos diferentes estratos.

Quanto à amostragem, é importante esclarecermos que em uma pesquisa qualitativa, o que se torna importante não é a representatividade numérica, e sim o aprofundamento e abrangência da compreensão. A amostra ideal segundo MINAYO (1996, p.102) (...) seria aquela capaz de refletir a totalidade nas suas múltiplas dimensões. Participaram deste estudo 16 adolescentes que freqüentavam a 7 a série das escolas sorteadas, com idade entre 12 e 14 anos. Foram entrevistados 4 alunos em cada escola, sendo sempre dois meninos e duas meninas. Este grupo de alunos foi considerado ideal, uma vez que as respostas ao nosso questionamento estavam se tornando repetitivas, caracterizando a exaustividade, representatividade, homogeneidade e pertinência aos objetivos do trabalho. E também devido ao fato de que o período considerado de maior risco à cárie encontra-se entre 13 e 16 anos de idade. Neste grupo, são as superfícies proximais de molares e pré-molares as mais suscetíveis à cárie e as doenças periodontais (BUISCHI \& AXELSSON, 1997).

Com o objetivo de identificar os entrevistados, numeramos as entrevistas de 1 a 16 , cada número foi precedido da letra "A" representando adolescente. Considerando que as entrevistas de número:

- 1 a 4 são da Escola EMEF. Profa. Neuza Michelutti Marzola /estrato baixo.

- 5 a 8 são da Escola EE. Alberto Santos Dumont/estrato médio-baixo.

- 9 a 12 são da Escola EMEF. Prof. Anísio Teixeira / estrato médio-alto.

- 13 a 16 são da Escola Particular. Vita et Pax /estrato alto.

Procuramos a direção das escolas, expusemos nosso projeto, e recebemos o aval para desenvolvê-lo nestes estabelecimentos. Previamente à realização das entrevistas obtivemos o termo de consentimento, assinado por pais, ou por responsáveis pelos adolescentes. É importante ressaltar que o presente estudo foi aprovado pelo Comitê de Ética em Pesquisa da Escola de Enfermagem de Ribeirão Preto da Universidade de São Paulo sob o protocolo n. 0055/1999.

\section{ANÁLISE DOS DADOS}

Percebemos através dos dados obtidos que a maioria dos adolescentes estudados recebem atendimento odontológico em consultório particular, mesmo se tratando dos estratos sociais menos privilegiados. O que nos faz refletir, que o sistema de atendimento público não está efetuando a universalização do atendimento odontológico, como preconizado pelo SUS. 
Tabela 1 - Atendimento Odontológico dos adolescentes segundo estrato social e local - Ribeirão Preto, 1999

\begin{tabular}{|c|c|c|c|c|c|c|c|c|c|c|c|c|c|c|c|c|}
\hline & \multicolumn{4}{|c|}{ E. Baixo } & \multicolumn{4}{|c|}{ E. Médio-baixo } & \multicolumn{4}{|c|}{ E. Médio-alto } & \multicolumn{4}{|c|}{ E. Alto } \\
\hline & A1 & $\mathrm{A} 2$ & A3 & A4 & AS & A6 & A7 & A8 & $\mathrm{Ag}$ & A10 & A11 & A12 & A13 & A14 & A15 & A16 \\
\hline Particular & & $\mathrm{x}$ & $\mathrm{x}$ & & & & & $\mathrm{X}$ & $\mathrm{x}$ & & $\mathrm{x}$ & & $\mathrm{x}$ & $\mathrm{x}$ & $\mathrm{x}$ & $\mathrm{X}$ \\
\hline Convênio & & & & & $\mathrm{X}$ & & & & & $\mathrm{X}$ & & $\mathrm{X}$ & & & & \\
\hline Público & & & & & & $\mathrm{x}$ & & & & & & & & & & \\
\hline Faculdade & $\mathrm{x}$ & & & & & & $\mathrm{x}$ & & & & & & & & & \\
\hline Público e Privado & & & & $\mathrm{X}$ & & & & & & & & & & & & \\
\hline
\end{tabular}

$\mathrm{E}=$ Estratos

A1 a A16 = alunos entrevistados

*Entende-se por Público: Posto de saúde e atendimento na escola

Apesar de existirem 277 cirurgiões-dentistas lotados na prefeitura de Ribeirão Preto, e de contarmos com vários programas voltados para essa faixa etária, infelizmente os adolescentes participantes do estudo ainda procuram o atendimento em consultório particular, convênios e faculdades de odontologia.

No que diz respeito à alimentação na escola, verificamos que $62,5 \%$ dos adolescentes estudados, utiliza a cantina da escola para a alimentação. Muitas vezes, deixam de consumir a merenda fornecida pela escola, que acreditamos ser bem mais balanceada que os alimentos que eles relataram consumir. Os alimentos relatados deram origem a Tabela a seguir:

Tabela 2 - Alimentos consumidos na cantina segundo os adolescentes estudados - Ribeirão Preto, 1999

\begin{tabular}{c|c|c|c|c|c}
\hline Salgados* & $\begin{array}{c}\text { Bala } \\
\text { Chiclete }\end{array}$ & Chocolate & Suco & $\begin{array}{c}\text { Cachorro } \\
\text { Quente }\end{array}$ & Refrigerante \\
\hline 8 & 7 & 5 & 1 & 1 & 5 \\
\hline
\end{tabular}

Obs. Esta tabela foi concebida a partir do número total de vezes que cada alimento consumido apareceu nas entrevistas. *Salgados: tanto os industrializados, como as coxinhas e etc.

Verificamos que a alimentação dos adolescentes na escola é cariogênica. Os salgados são considerados alimentos cariogênicos, e os refrigerantes também. MATEOS (1999) afirma que os refrigerantes além de possuírem açúcar, apresentam $\mathrm{pH}$ ácido, que favorece a desmineralização dos dentes. Ainda verificamos um grande número de adolescentes que consomem balas e chicletes, o que também é preocupante, pois a presença do açúcar e o tempo que essas substâncias permanecem em contato com os dentes, favorecem a desmineralização do esmalte.

\subsection{Temáticas do estudo}

Utilizamos a técnica de análise de conteúdo, na modalidade de análise temática através da qual encontramos os núcleos de sentido, que deram origem as seguintes temáticas: aparência pessoal, sexualidade, emprego, e saúde geral.

A aparência pessoal é uma preocupação para os adolescentes estudados, os dentes são encarados como um recurso para ficar mais bonito, para a aceitação social.

A3: Eu quis corrigir os dentes para sei lá (risos), para ficar mais bonito também, uma coisa assim que vai ser melhor para mim.

A16: Tem gente que tem preconceito de que se não tem dente é pobre, já foi preso, não pode trabalhar, tá desempregado...

Segundo BALDWIN (1980), um grande número de estudos tem documentado os efeitos saudáveis da atratividade nos relacionamentos interpessoais, e que a aparência é uma chave para o sucesso nas relações. O autor cita vários trabalhos que mostram claramente a preocupação dos adolescentes com a aparência, e sua relação com a auto-imagem e auto-estima. Percebemos que no grupo de adolescentes estudados esta preocupação também está sempre presente.

A5: Se você conversar com a pessoa, ela sai de perto, ela não consegue conversar com você, por causa do mau-hálito, tem dois moleques na minha classe que acontece isso. Você tem que conversar meio afastado.

A4: Porque eu pelo menos, a primeira coisa que vejo na pessoa é o dente.

É através da boca que também nos comunicamos, é através dela que desenvolvemos o sorriso, e também com ela que beijamos. Portanto é natural que seja esta, um motivo de preocupação para os adolescentes. A boca está intimamente relacionada com a sexualidade, seja através do beijo, através do aroma do hálito em conversas mais próximas, ou ainda através do contato sexual.

A2: Os dentes feio... atrapalha o namoro.... acho que é só

A5: Se você vai ficar com alguma menina, também é bom estar de boca limpa 
A14: Porque eu acho que ninguém da parte do menino, quanto da menina vai querer ficar, namorar, com alguém com os dentes estragados. Eu pelo menos não queria (risos).

O namoro é uma importante etapa no desenvolvimento do ser humano, trata-se de um relacionamento social afetivo-sexual. No namoro vem à tona a auto-imagem, as imagens internalizadas e as externas do homem e da mulher, o modelo de relacionamento dos pais, a revisão da matriz de identidade, a visão com perspectiva de futuro. Principalmente a partir da puberdade e no início da adolescência, a auto-imagem tem muita relação com a auto-estima e a auto-avaliação. Ter boa auto-estima é gostar e valorizar a si mesmo (TIBA, 1986).

A sexualidade é, sobretudo, um elemento estruturador da identidade do adolescente. E essa função estruturante é, em grande parte, realizada através da representação mental que o adolescente tem de seu corpo, ou seja, através de sua imagem corporal (OSÓRIO, 1992, p.16).

Portanto, sendo o namoro uma condição de saúde, uma fase do desenvolvimento, é preciso que os adolescentes consigam viver esta etapa de uma forma saudável, e para isso é necessário que não estejam com a saúde e nem com a estética bucal comprometida.

No que diz respeito ao emprego, a identidade ocupacional para o adolescente é um aspecto da própria identidade pessoal, portanto, submetida às mesmas leis e dificuldades. Tanto a identidade ocupacional como a pessoal, devem ser entendidas como a contínua interação entre fatores internos e externos ao adolescente (ENDERLE, 1988).

Em nossa sociedade atual onde podemos constatar altos índices de desemprego, em um mercado de trabalho tão saturado, não causa espanto a preocupação precoce com o trabalho pelos adolescentes estudados, e a importância dada por estes aos seus dentes, no sentido de contribuírem para arranjarem melhores ocupações.

A4: Se a pessoa não cuidar bem dos dentes, na hora de arrumar emprego é mais difícil

A13: Porque tem entrevista de emprego que se a pessoa tiver dente estragado, vão achar que a pessoa não tem potencial para trabalhar, e às vezes é o contrário. Às vezes a pessoa tem o dente lindo, e é a que não tem potencial para trabalhar.

Neste singular momento, o jovem mergulha dentro de si buscando identificar suas metas, descobrir suas capacidades e habilidades, permitindo sentir-se capaz, competente, realizador, útil para si próprio e para os demais, sendo um membro participante da sociedade.

Os adolescentes geralmente gostam de trabalhar.
O trabalho dá ao adolescente a posição de adulto, pois implica na responsabilidade de produzir algo e ser remunerado pelo que realiza.

Sabemos da importância que os dentes têm em relação à saúde geral, podendo perceber através dos adolescentes estudados, que eles reconhecem esta importância.

A4: Ah... para ter uma boa saúde bucal. Eu acho que agente tem que cuidar de tudo, não só dos dentes, pois faz parte do nosso corpo.

A9: Se não tratar dos dentes, vai ficar tudo com os dente podre, com mau-hálito.

CAPRA (1982) nos lembra que saúde é um fenômeno multidimensional, que envolve aspectos físicos, psicológicos e sociais, todos interdependentes. Partindo deste conceito, temos em mente que a importância da saúde bucal para os adolescentes, perpassa todas estas dimensões, seja no aspecto físico, onde eles relatam a presença da "dor", da necessidade de poder "mastigar em ordem", do perigo de "câncer bucal", na dimensão psicológica, que se mostra presente na importância da aparência pessoal, em "estar mais bonito para as meninas", em "não ser mais xingada de dentuça", em "ter os dentes bonitos para beijar", e ainda nas dimensões sociais, onde mostram que "por causa do mauhálito tem que conversar meio afastado". Conhecendo tudo isto, acreditamos que devemos transmitir os conhecimentos adquiridos e acumulados pelos dentistas durantes tantos anos, através da educação em saúde.

\section{CONSIDERAÇÕES FINAIS}

Vimos através de alguns aspectos históricos, que a odontologia passou por muitas fases, desde a odontologia dos tempos mais remotos, quando era praticada por barbeiros, sangradores que trabalhavam nas feiras, e praticamente só extraíam os dentes sem anestesia, provocando intensas dores, caminhando até o modelo curativo/ restaurador, onde felizmente se percebeu que o enfoque curativo constitui uma visão estreita da realidade, e finalmente evoluindo para o modelo preventivo/ promoção de saúde. Este modelo permitiu que os profissionais da área odontológica começassem a ter uma visão mais holística de seus pacientes, compreendendo suas reais necessidades, seus medos, seus desejos. Enfim, colaborando para que esses possam caminhar para a saúde.

Acreditamos que esse caminhar será através da educação em saúde, pois conhecer o problema ou o perigo, já faz com que este fique menor, e mais fácil de se resolver. Conhecer o que motiva o adolescente, seja música, namoro, aparência, emprego ou esporte, é 
fundamental para termos a empatia necessária para lhe transmitir o conhecimento. Entendemos por motivação, a configuração de motivos de uma pessoa, ou o apelo a eles por outra pessoa para fins determinados. Do ponto de vista do ensino, a motivação compreende a ativação, a manutenção e a direção do interesse (BORDENAVE \& PEREIRA, 1995).

Percebemos que os fatores que mais deixam os adolescentes participantes do estudo, motivados para cuidar de sua saúde bucal são: a aparência pessoal, a sexualidade, o emprego e a saúde de um modo geral. Conhecendo estas motivações, acreditamos ser possível planejar formas de educação em saúde que despertem o interesse, deixando-os mais envolvidos, permitindo assim, que a aprendizagem se relacione com o universo dos adolescentes, deixando-os mais e participantes.

Acreditamos que o contato com a comunidade é muito frutífero no sentido de nos aproximarmos das necessidades reais dos adolescentes, pois sabendo que motivos os levam a procurar atendimento odontológico, teremos subsídios para orientá-los dos desequilíbrios que causam doenças, antes que os mesmos venham procurarnos para tratamento e recuperação.

Tendo tudo isso em mente, devemos inserir as ações educativas em todas as atividades desenvolvidas pelo profissional, pois desta forma estaremos nos aproveitando do interesse da pessoa em determinado assunto para transmitir-lhe nossos conhecimentos. Tendo sempre o cuidado de usar uma linguagem clara, simples, e adequada à cultura e idade da pessoa.

Devemos também nos lembrar que, para que ocorra uma boa transmissão de conhecimento é imprescindível um bom relacionamento interpessoal. Mas, infelizmente, ainda existe um pouco da imagem negativa do dentista. Talvez, esta imagem do dentista tenha origem na forma mutiladora e dolorosa com que o tratamento era realizada no passado, ou ainda no fato que sempre os profissionais tratavam a doença, e não o doente.

O paciente normalmente ficava insatisfeito com o resultado do tratamento, pois muitas vezes, após a restauração de um dente, novas lesões de cárie apareciam, fazendo com que o paciente ficasse impotente em relação a sua saúde. Afinal, este não era orientado, nem instruído, quanto aos desequilíbrios causadores de sua doença.

Muito importante também, é o caminhar no sentido de ter uma visão mais abrangente de nossos pacientes, integrando aspectos biológicos, psicológicos, sociais, ambientais e multidisciplinares.

Acreditamos que devemos ampliar nossos conhecimentos em relação às estratégias de ensino e aprendizagem, que se constituem em métodos e meios para que o profissional possa organizar as condições de aprendizagem, visando mudanças de comportamento necessárias à manutenção, aquisição e promoção de saúde.

Acreditamos ainda, que conhecendo o que motiva o adolescente, poderemos programar formas de educação em saúde, tão eficazes como os teatrinhos e jogos são para as crianças, para podermos atingir nossas metas no caminho da educação em saúde, para, enfim, promovermos a tão almejada saúde.

\section{THE IMPORTANCE OF BUCAL HEALTH FOR ADOLESCENTS OF DIFFERENT SOCIAL STRATA OF RIBEIRÃO PRETO}

The objective of the present study is to know the importance of buccal health for adolescents of different social strata, identifying the importance of dental aesthetics, and the care that these students take in relation to their buccal health. The methodological process adopted in this investigation is of qualitative nature, using as technique of collection of data the semistructured interview. We know the importance of buccal health in several contexts of their lives, as in their personal appearance, sexuality, employment, and general health. This investigation allows us to know the motivations of adolescents to preserve their buccal health, and we believe to be so valid to develop health promotionh through health education.

KEY WORDS: adolescence, education in health, dental aesthetics, buccal health

\section{LA IMPORTANCIA DE LA SALUD BUCAL PARA LOS ADOLESCENTES DE DIFERENTES ESTRATOS SOCIALES DEL MUNICIPIO DE RIBEIRÃO PRETO}

El objetivo del presente estudio es conocer la importancia de la salud bucal para los adolescentes de diferentes estratos sociales, identificando la importancia de la estética dental y el cuidado que estos realizan en relación con su salud bucal. El proceso metodológico adoptado en esta investigación es de naturaleza cualitativa, utilizando como técnica de recolección de datos la entrevista semi-estructurada. Conocimos la importancia de la salud bucal en varios contextos de sus vidas, como en la apariencia personal, en la sexualidad, en el empleo y en la salud en general. Esta investigación nos permitió conocer las motivaciones que tienen los adolescentes para preservar su salud bucal, lo cual creemos será muy valioso en desarrollar programas de promoción de la salud a través de la educación en salud. 
REFERÊNCIAS BIBLIOGRÁFICAS

01. BALDWIN, D.C. Appearance and aesthetics in oral health. Community Dent. Oral Epidemiol., v. 8, n. 5, p. 244-256, 1980.

02. BORDENAVE, J.D.; PEREIRA, A.M. Estratégias de ensino - aprendizagem. Petrópolis: Vozes, 1995. 312p.

03. BUISCHI, Y.P.; AXELSSON, P. Controle mecânico da placa dental realizado pelo paciente. In: KRIGER, L. (Org.). Promoção de saúde bucal. São Paulo: Artes Médicas, 1997. p. 113-127.

04. CAPRA, F. O ponto de mutação (The turning point). Trad. de Álvaro Cabral. São Paulo: Cultrix, 1982. $447 p$.

05. CAVALCANTI, R.C. Adolescência. In: VITIELLO, N. et al. Adolescência hoje. São Paulo: Roca, 1988. p. 5-27.

06. CHAVES, M.M. Odontologia social. São Paulo: Artes Médicas, 1986. 448p.

07. DeBIASE, C.B. Dental health education: theory and pratice. Pennsylvania: Lea \& Febiger, 1991.314p.

08. ENDERLE, C. Psicologia da adolescência: uma abordagem pluridimensional. Porto Alegre: Artes Médicas, 1988. 76p.

09. GAGNÉ, R.M. Como se realiza a aprendizagem. Trad. Therezinha Maria RamosTovar. Rio de Janeiro: Livros Técnicos e Científicos, 1974. $270 \mathrm{p}$.

10. GOLDSTEIN, R.E. Estética em Odontologia. Rio de Janeiro: Guanabara Koogan, 1980.

11. INFANTE, D.P. Desenvolvimento psicossocial. In: MARCONDES, E. (Coord.) Pediatria básica. São Paulo: Sarvier, 1994. v. 1, p. 550-552.

12. JENNY, J.; PROSHEK, J.M. Visibility and prestige of occupations and the importance of dental appearance. J. Can. Dent. Assoc., v. 12, p. 987989, 1986.
13. MALTZ, M.; CARVALHO, J. Tratamento da doença cárie. In: KRIGER, L. (Org.). Promoção de saúde bucal. São Paulo: Artes Médicas, 1997. p. 95-111.

14. MATEOS, A. Brasileiros comem cada vez mais e com pior qualidade. Revista da APCD, v. 53, n. 1, p. 8-20, Jan/Fev. 1999.

15. MENDES, I.J.M. Promoção de saúde: caminhando para o único. Ribeirão Preto, 1996. Tese (Livre Docência) - Escola de Enfermagem de Ribeirão Preto, Universidade de São Paulo.

16. MINAYO, M.C.S. O desafio do conhecimento: pesquisa qualitativa em saúde. São Paulo: Hucitec, 1996. 269p.

17. NARVAI, P. C. Odontologia e saúde bucal coletiva. São Paulo: Hucitec, 1994. 113p.

18. OSÓRIO, L.C. Adolescente hoje. Porto Alegre: Artes Médicas, 1992. 103p.

19. RIBEIRO, R.P.P. Indicadores de hábitos dietéticos e aspectos cognitivos e comportamentais relacionados aos distúrbios de conduta alimentar em adolescentes do sexo feminino. Ribeirão Preto, 1999. Tese (Doutorado) Faculdade de Medicina de Ribeirão Preto, Universidade de São Paulo.

20. SILVA, G.B. Critérios de estratificação social. Rev. Saúde Pública, São Paulo, v. 15, p. 38-45, 1981.

21. STAVENHAGEN, R. Estratificação social e estrutura de classes. In: LUKÁCS, G. et al. Estrutura de classes e estratificação social. Rio de Janeiro: Zahar, 1966. p.117-148.

22. TIBA, I. Puberdade e adolescência: desenvolvimento biopsicossocial. São Paulo: Ágora, 1986. 236p.

23. WEYNE, S.C. A Construção do paradigma de promoção de saúde: um desafio para as novas gerações. In: KRIGER, L. (Org.). Promoção de saúde bucal. São Paulo: Artes Médicas, 1997. p.1-26. 